\title{
DESIGN E AGRICULTURA FAMILIAR: AÇÕES DE VALORIZAÇÃO E IDENTIFICAÇÃO EM SANTA CATARINA
}

Giselle Schmidt Alves Díaz Merino

Universidade Federal de Santa Catarina

gisellemerino@gmail.com

Eugenio Andrés Díaz Merino

Universidade Federal de Santa Catarina

eugenio.merino@ufsc.br

\author{
Marina Cuneo Aguiar \\ Universidade Federal de Santa Catarina \\ marina.cuneo.aguiar@posgrad.ufsc.br \\ Ricardo Triska \\ Universidade Federal de Santa Catarina \\ ricardo.triska@ufsc.br \\ Danilo Pereira \\ Empresa de Pesquisa Agropecuária e \\ Extensão Rural de Santa Catarina \\ danilo.pereira@epagri.sc.gov.br
}

Resumo: Com destaque na produção de alimentos no mundo, a agricultura familiar é também fator essencial na geração de emprego e renda e para o desenvolvimento local sustentável. No entanto, seus produtores ainda enfrentam desafios para se estabelecerem no mercado. Diante deste contexto, identificam-se oportunidades de contribuição do design. Este artigo objetiva identificar quais ações podem ser propostas pelo design visando à valorização e identificação dos produtos da agricultura familiar. Como resultados, apresentam-se ações desenvolvidas e em desenvolvimento junto aos empreendimentos nos últimos quinze anos, por meio de projetos de identidade visual, embalagens, rótulos, dentre outros. Complementam estes resultados pesquisas nos pontos de venda com consumidores que demonstram a melhoria das vendas e da percepção da qualidade aparente dos produtos, por meio das ações do design.

Palavras-chave: design, gestão de design, agricultura familiar, identificação, valorização.

Abstract: Highlighting in the global food production, family farming is also a key factor in generating employment and income and to sustainable local development. However, its producers still face challenges in establishing themselves in the market. In this context, In this context, opportunities to design's contribution were identified. This article aims to identify what actions can be proposed by design for valorization and identification products of family farming. The results present developed and developing actions in the last fifteen years, through visual identity design, packaging, labels and others. Complementing these results researchs at point of sale with consumers showing improved sales and perception of the apparent quality of the products, through the design actions.

Keywords: design, strategic design management, family farming. 


\section{INTRODUÇÃO}

Fernández e Bonsiepe (2008) afirmam que, nas últimas décadas, vem sendo observada uma aproximação entre o design e um público mais diversificado, possibilitando a participação do design como fator efetivo de desenvolvimento social, econômico e tecnológico.

Neste contexto, destaca-se a agricultura familiar e sua contribuição para a segurança alimentar, a geração de emprego e renda, a redução da pobreza e o desenvolvimento local sustentável. Segundo o AIAF - Ano Internacional da Agricultura Familiar $^{1}$ (2014), a agricultura familiar inclui todas as atividades agrícolas de base familiar, envolvendo produções agrícola, florestal, pesqueira, pastoril e aquícola que são gerenciadas e operadas por uma família e, predominantemente, dependentes de mão-de-obra familiar.

No que se refere à produção de alimentos, de acordo com a FAO - Organização das Nações Unidas para Alimentação e Agricultura (2014b), aproximadamente $80 \%$ dos alimentos consumidos no mundo provêm da agricultura familiar, sendo também 0 principal responsável pela comida que chega às mesas das famílias brasileiras, respondendo por cerca de $70 \%$ da produção nacional (PORTAL BRASIL, 2015). Possui também papel fundamental para a segurança alimentar, como fonte de alimentos saudáveis e de qualidade, na geração de emprego e renda para um grande número de pessoas vivendo na pobreza nas comunidades rurais, além da contribuição para o desenvolvimento local sustentável por meio de práticas menos agressivas ao ambiente (FAO, 2014a; ARIAS et al, 2013). Em Santa Catarina, a riqueza e a diversidade do campo colocam o estado em posição de destaque no cenário nacional. Segundo dados da FETAESC - Federação dos Trabalhadores Rurais Agricultores e Agricultores Familiares do Estado de Santa Catarina (2015), o estado é um dos cinco principais produtores nacionais. É, ainda, o maior polo produtor de pescados do Brasil, sendo que na Grande Florianópolis o destaque é para o cultivo de ostras e mexilhões, a chamada malacocultura (GOVERNO DO ESTADO DE SANTA CATARINA, 2016). A agricultura familiar ocupa papel representativo no estado, abrangendo um universo de cerca de 180 mil famílias, mais de $90 \%$ da população rural catarinense (BENEZ et al, 2010).

No entanto, estes produtores familiares ainda enfrentam diversos desafios, principalmente em relação à comercialização. De acordo com a FAO (2014b), estes incluem a globalização do setor alimentar, as alterações climáticas, a falta de serviços financeiros adequados, o pobre acesso ao mercado, a insegurança quanto a posse de terra e políticas que não respondem às suas necessidades. Outra fragilidade refere-se à baixa renda obtida com a atividade agrícola. Por se tratarem de commodities, a agregação de valor, que proporciona maiores rendimentos na atividade agrícola, acaba se tornando limitada, principalmente nos produtos in natura (ARAUJO, 2007). Segundo Teixeira (2011), em geral, estes grupos produtivos de pequeno porte exploram pouco seus produtos e não apresentam diferenciais. Em pesquisa realizada por Altamann, Mior e Zoldan (2008), em Santa Catarina, sobre as perspectivas para o sistema agroalimentar e o espaço rural no estado em 2015, apresenta as estratégias comerciais frequentemente mencionadas pelos entrevistados e utilizadas como indicativos do perfil da produção regional no futuro: agregação de valor; diferenciação do produto;

\footnotetext{
${ }^{1}$ Iniciativa da FAO, que estipulou 2014 como o ano internacional da agricultura familiar. Disponível na internet por http em: <http://www.fao.org/family-farming-2014/pt/>. Acesso em 24 abr. 2016.
} 
desenvolvimento em design e embalagem; melhoria da qualidade, higiene e limpeza; cumprimento de prazos e fidelização de clientes.

Tais panoramas reforçam a participação do design que, quando utilizado estrategicamente, busca compreender as necessidades e os objetivos desses produtores e pode contribuir para sua valorização e identificação com 0 desenvolvimento de projetos. Marcas gráficas, embalagens, rótulos, sites, folders, entre outros materiais, beneficiam os grupos produtivos e seus produtos na melhora de sua qualidade; bem como para sua identificação e comunicação com o consumidor, ao evidenciar, por meio de formas, cores e materiais, aspectos culturais locais e de produção que proporcionarão diferenciação no mercado (SEBRAE, 2015; TEIXEIRA, 2011).

Diante do contexto exposto, este artigo objetiva identificar quais ações podem ser propostas pelo design visando à valorização e identificação dos produtos da agricultura familiar. Quanto aos procedimentos metodológicos, o artigo encontra-se estruturado da seguinte forma: 1) organização cronológica dos projetos; 2) identificação das fragilidades e 3) apresentação das ações de design. Do ponto de vista de seus objetivos, caracteriza-se como descritivo; quanto a sua natureza, aplicada; em relação aos procedimentos técnicos, classifica-se como bibliográfica e documental; e quanto à forma de abordagem, qualitativa. Na pesquisa aplicada, nos 44 casos desenvolvidos pelo NGD/LDU UFSC - Núcleo de Gestão de Design \& Laboratório de Design e Usabilidade da Universidade Federal de Santa Catarina, foram realizados, inicialmente, levantamentos de campo, com utilização formulários e questionários, que permitiram caracterizar o perfil dos produtores, informações sobre produto e produção; bem como levantar hábitos e costumes dos consumidores, tendências de mercado, pesquisas de similares e concorrentes nos pontos de venda, além de aspectos regionais, geográficos, culturais, ambientais e sociais. Também foram realizados registros fotográficos e em vídeo para complementar as informações coletadas.

\section{DESENVOLVIMENTO}

No contexto das contribuições do design para os produtores da agricultura familiar serão apresentados casos desenvolvidos no estado de Santa Catarina durante os últimos quinze anos (Figura 1) em parceria com a EPAGRI - Empresa de Pesquisa Agropecuária e Extensão Rural de Santa Catarina.

Em 2002 e 2003, o projeto iniciou na região de Mafra com atuação em quatro casos. Em 2003 e 2004, foram desenvolvidos projetos com mais três empreendimentos nas cidades de Porto União, Canoinhas e Itapiranga. Nos anos de 2004 e 2005, foram trabalhados seis casos nas cidades Blumenau, Palma Sola, São Miguel do Oeste, Videira, Urussanga e Chapecó. Em 2010, iniciou-se o projeto internacional no Peru e na Venezuela, além do Brasil (Santa Catarina), nas cidades de Urussanga e Garopaba. Em 2008, a atuação aconteceu em Florianópolis, com a AMPROSUL. Em 2010, em Governador Celso Ramos com a Mar de Açores. Desde 2014, a parceria com a Epagri segue por meio do projeto Gestão de Empreendimentos Rurais e Pesqueiros, com atuações em vinte e seis empreendimentos nas regiões de Joinville e Blumenau. 


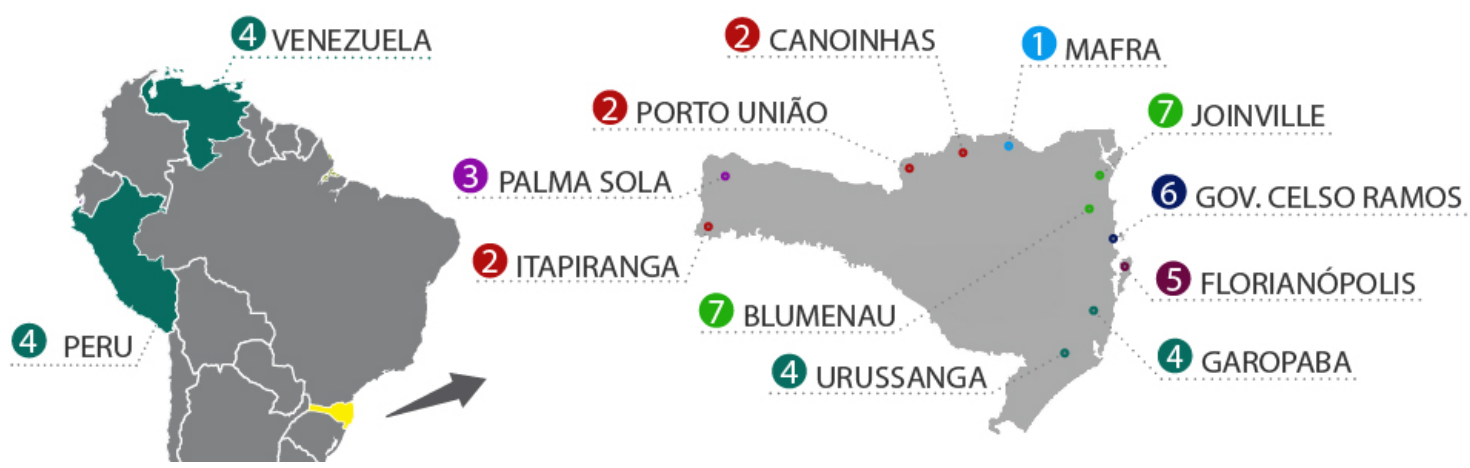

Figura 1 - Mapas com as cidades dos empreendimentos familiares, indicando a ordem de atuação.

Fonte: Elaborado pelos autores, com base na pesquisa realizada.

\subsection{Mafra}

Os projetos voltados para a valorização e identificação da agricultura familiar no estado iniciaram em 2002, na cidade de Mafra, localizada ao Norte de Santa Catarina. Em um primeiro momento, o projeto envolveu quatro casos, sendo: Associação Vitória, produtora de bolachas caseiras; Apromel, produtora de mel; Sr. Ralf, criação de frango caipira; e Portal Verde, produção de pepinos em conserva. Buscando a multidisciplinaridade da gestão de design, faziam parte da equipe profissionais da área de Design, Engenharia de Alimentos, Agronomia e Ciências da Informação².

A demanda identificada junto aos produtores foi de fortalecer a imagem dos produtos alimentícios originados da região por meio do design. A partir de um levantamento, foi possível verificar a qualidade dos produtos e a inexistência de um elemento que fortalecesse e identificasse sua região de origem. Constatou-se a existência de uma série de grupos produtores e associações, cada um com nome próprio, que produziam e comercializavam seus produtos. Verificou-se também um distanciamento progressivo entre os produtores e os consumidores; o aumento da preocupação do consumidor em relação à origem dos produtos alimentícios disponíveis no mercado; a multiplicação de tecnologias e produtos nas últimas décadas; e a abertura do mercado através de acordos e comunidades de comércio.

Com base no cenário observado, foram propostas ações de criação de um selo da região, visando à identificação da origem e o fortalecimento regional; bem como a criação de embalagens, buscando a identificação dos produtos, a melhoria em questões de funcionalidade, a comunicação de informações obrigatórias, além de ressaltar características culturais diferenciadoras (Figura 2).

\footnotetext{
2 Este projeto teve sua origem no edital lançado pela Fundação de Ciência e Tecnologia de Santa Catarina no ano de 2001 e contou com apoio do Instituto CEPA/SC e da Faculdade Barddal, especificamente o curso de Design, além do apoio da própria Universidade Federal de Santa Catarina, a qual o NGD/LDU está vinculado.
} 


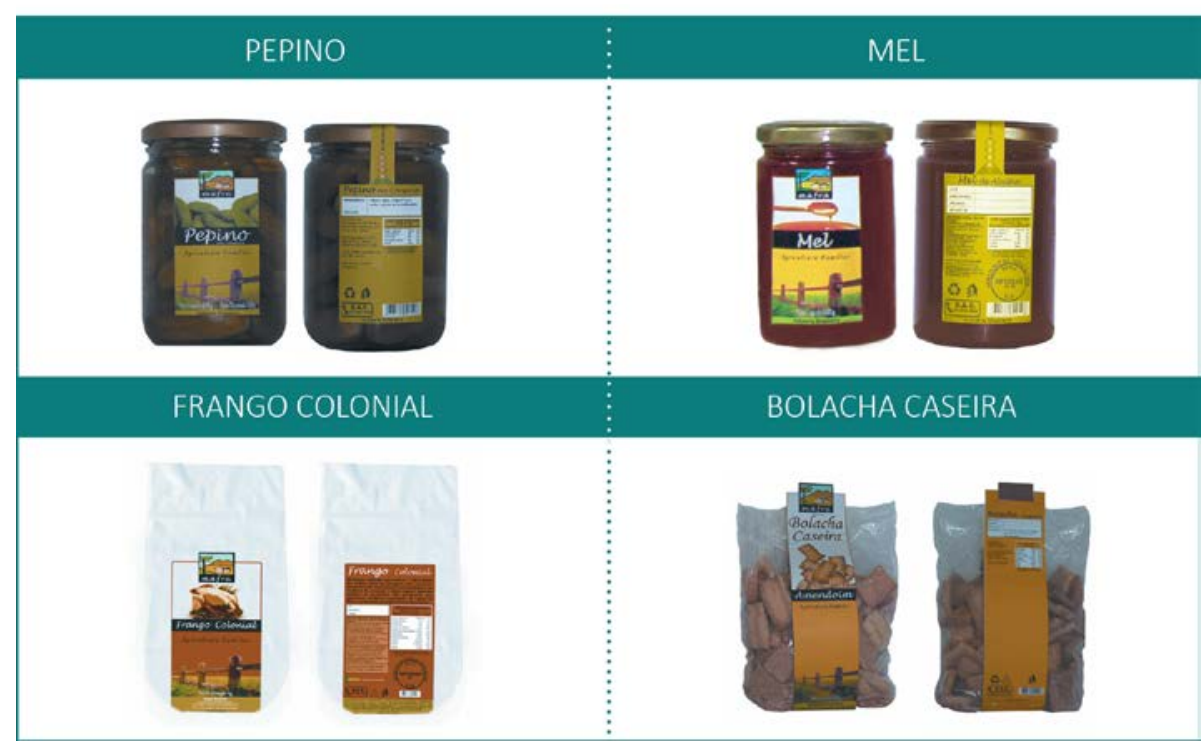

Figura 2 - Rótulos e embalagens desenvolvidos para os produtos com aplicação do selo de Mafra. Fonte: acervo NGD/LDU UFSC.

Após o desenvolvimento das ações, foi realizada uma pesquisa de ponto de venda em um mercado da cidade, de modo a verificar e obter informações relativas à aceitação dos produtos por meio de entrevistas. Nas prateleiras do mercado foram inseridas a mesma quantidade de produtos com as embalagens antigas (40) e as novas propostas (40), que ficaram à venda durante três dias. A saída dos produtos foi contabilizada e observou-se que os produtos com embalagens reformuladas tiveram maior saída ou preferência de escolha. No primeiro dia, das novas embalagens de pepino foram vendidas 16 e das embalagens antigas tinham saído 9. No segundo dia, a contabilização foi de 38 e 16, respectivamente. Verificou-se uma clara tendência de maior consumo pelas novas embalagens, e dentro os motivos identificados: aparência, careça das informações, identificação local e do produtor rural, dentre outras.

\subsection{Porto União, Canoinhas e Itapiranga}

Em 2003, iniciou-se outro projeto por meio da parceria com o Instituto CEPA Centro de Socioeconomia e Planejamento Agrícola da EPAGRI, com três grupos de produtores da agricultura familiar do estado: em Porto União, com a Éfruta Associação de Produtores Ecológicos de Porto União, que produz e comercializa hortifrutigranjeiros; em Canoinhas, a AGRUPAR - Associação de Grupos de Pequenos Agricultores de Canoinhas e Região, que tem como principais produtos o suco de uva, o molho de tomate e a geleia de amora; e em Itapiranga, com a Beleza, pequena indústria que produz e comercializa derivados da cana de açúcar. A atuação com os grupos visou, principalmente, atender às necessidades de melhoria da qualidade aparente e de origem dos produtos e de identificação dos grupos, que em sua maioria possuem deficiências de embalagem/rótulos e marca gráfica, e às dificuldades nos aspectos de legislação que regulamentam a rotulagem, de modo a contribuir para a garantia de segurança, rastreabilidade e confiabilidade nas relações comerciais.

Para a AGRUPAR foram propostos o desenvolvimento de marca e selo de identificação para os produtos (contendo marca e identificação de origem), que representem sua finalidade; e a melhora da aparência dos PDVs, visando transmitir aos 
consumidores a percepção de organização, com foco no desenvolvimento de aventais, bonés, camisetas, sacolas e materiais de divulgação e esclarecimento das características dos produtos comercializados. Para a Éfruta, foram definidas como ações a criação da marca gráfica e de rótulos, a análise das embalagens atualmente utilizadas e a produção de amostras-piloto para pesquisa com o público. Para a Beleza, foram propostos o estudo dos rótulos existentes e o desenvolvimento de novas propostas. Os resultados podem ser visualizados na Figura 3 abaixo.

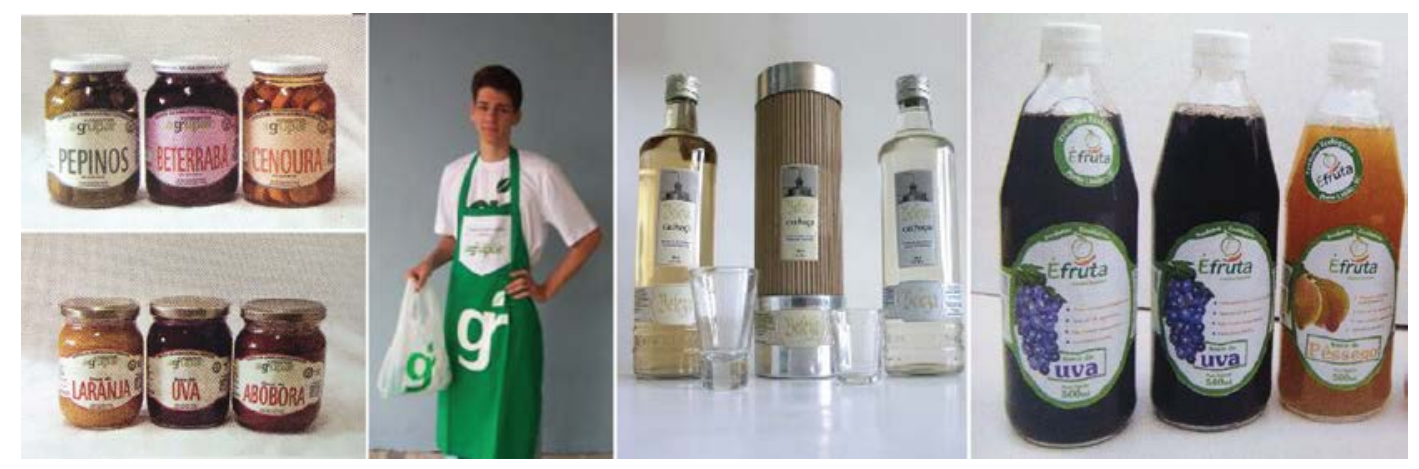

Figura 3 - Marcas gráficas, embalagens e rótulos desenvolvidos para AGRUPAR, Beleza e Éfruta respectivamente.

Fonte: acervo NGD/LDU UFSC.

Para Éfruta e AGRUPAR também foi realizada pesquisa de qualidade aparente no PDV. Os entrevistados consideraram que os produtos com as novas propostas estão melhor identificados, com informações a respeito de sua procedência/origem e características diferenciadoras (sem uso de agrotóxicos; produzido por pequenos agricultores), e aparentam maior qualidade, destacaram também as embalagens mais práticas. Os projetos desenvolvidos para a AGRUPAR e a Beleza foram reconhecidos no prêmio Design Catarina - Micro e Pequena Empresa, promovido pelo Instituto Euvaldo Lodi/SC, por meio do Centro de Design, com o apoio do SEBRAE/SC e da Rede Design Catarina, em 2005.

\subsection{Palma Sola}

Iniciado em 2004, o projeto realizado em Palma Sola, no extremo oeste de Santa Catarina, contou com a participação do produtor unifamiliar de nome Hermes de Ré, com produção voltada a cachaça. Conhecido pelos consumidores pela cachaça artesanal de boa qualidade, o produto é comercializado em garrafas PETs (Polietileno Tereftalato) reaproveitadas ou em garrafões de 5 litros. Além das pesquisas usuais a respeito do produtor, produção e produto, também foi realizada uma busca junto ao Instituto Nacional da Propriedade Industrial (INPI) para verificação de registro do nome. A demanda identificada referia-se à representação do empreendimento, atentando à questão de identificação de origem, especificamente, neste caso, ao produtor e aspectos geográficos marcantes; evidenciar e resgatar também valores oriundos da agricultura familiar e produção artesanal, bem como atentar para os aspectos de legislação vigentes. Diante dos requisitos do projeto, foi desenvolvida a identidade visual, abrangendo a marca gráfica e as principais aplicações (embalagens e rótulo). Os resultados podem ser visualizados na Figura 4 a seguir. 


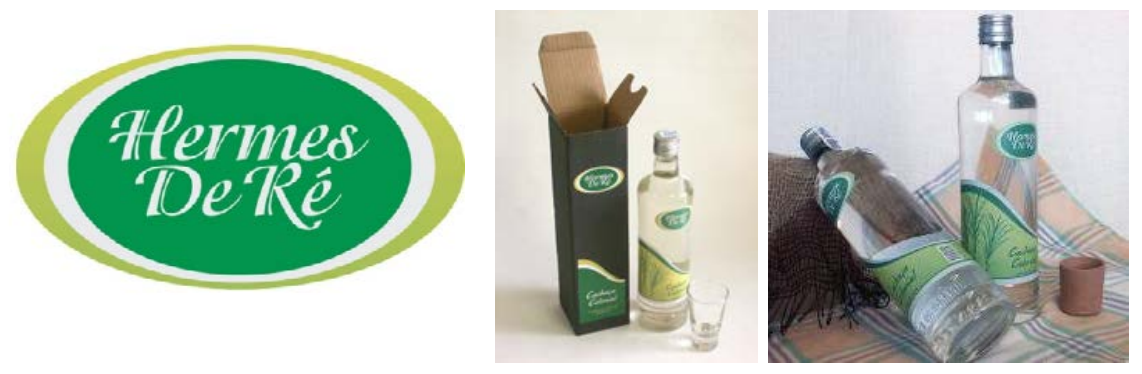

Figura 4 - Marca gráfica, embalagens e rótulos propostos para a Hermes de Ré.

Fonte: acervo NGD/LDU UFSC.

O projeto também foi destaque no Prêmio Design Catarina Micro e Pequena Empresa - 2005.

\subsection{Projeto Internacional: Brasil, Peru e Venezuela}

Em 2010, o projeto internacional foi desenvolvido com a participação do Brasil, Venezuela (Universidad de los Andes) e Peru (Peru Green Day-Pontificia Universidad Catolica del Peru), e contou com o apoio da Fundação de Amparo a Pesquisa e Inovação do Estado de Santa Catarina (FAPESC) e do Conselho Nacional de Desenvolvimento Científico e Tecnológico (CNPq).

No Peru, os trabalhos foram realizados com as associações Prolucuma produtores da lúcuma (uma fruta tipicamente peruana), e a Apropica - produtores do pisco (aguardente de uva produzida no Peru). Na Prolucuma foram identificados como principais objetivos: exportar com uma marca coletiva associativa, sendo destaque no exterior país com identificação para que seja reconhecida sua procedência peruana, buscando assim uma maior visibilidade, despertando novos sócios e também incrementando o mercado interno. Para isso, propôs-se o desenvolvimento de marca gráfica e principais aplicações (caixas para transporte do produto, adesivo de frota e material básico de papelaria). Na Apropica, a demanda identificada foi da por meio da marca coletiva, visto que a associação cresceu muito no mercado internacional, além de ressaltar a denominação de origem do Pisco no país. Como ações, foram propostos o desenvolvimento da marca gráfica e principais aplicações (rótulo, caixas para transporte do produto, adesivo de frota e material básico de papelaria). Os resultados podem ser visualizados na Figura 5 abaixo.

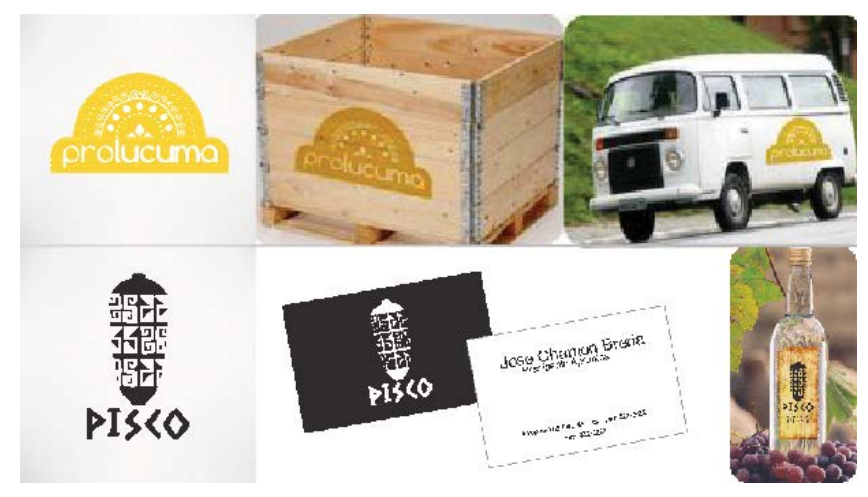

Figura 5 - Materiais desenvolvidos para a Prolucuma e a Apropica.

Fonte: acervo NGD/LDU UFSC. 
Na Venezuela ${ }^{3}$, a atuação ocorreu com os empreendimentos Lácteos Santa Rosa - pequeno estabelecimento leiteiro; Asopavilme - produtores de vinhos e licores de amora; e com as cooperativas Mesa Julia e Chocomelia - produtoras de cacau e de produtos artesanais à base do fruto.Observou-se que a Lácteos Santa Rosa não incorporava em seus produtos o apelo regional, resgatando características e termos locais. Também foi percebida dificuldade no acondicionamento dos produtos que, pela pouca variedade de materiais para embalagem, sofre prejuízos. Como ação, propôs-se o desenvolvimento de uma marca de certificação ${ }^{4}$, que contribuirá para atestar a qualidade dos queijos e proporcionar uma boa percepção por parte do consumidor, além de embalagens e rótulos para acondicionamento, proteção e identificação dos produtos. Na Asopavilme observou-se como uma necessidade a reunião dos produtores numa única marca, na qual todos estejam regularizados e produzam produtos de boa qualidade, propiciando a melhoria de sua estrutura (aquisição de maquinários e terras). Previu-se o desenvolvimento de uma marca coletiva ${ }^{5}$, de modo a identificar a produção e representar a unificação dos produtores. Os resultados podem ser vistos na Figura 6.

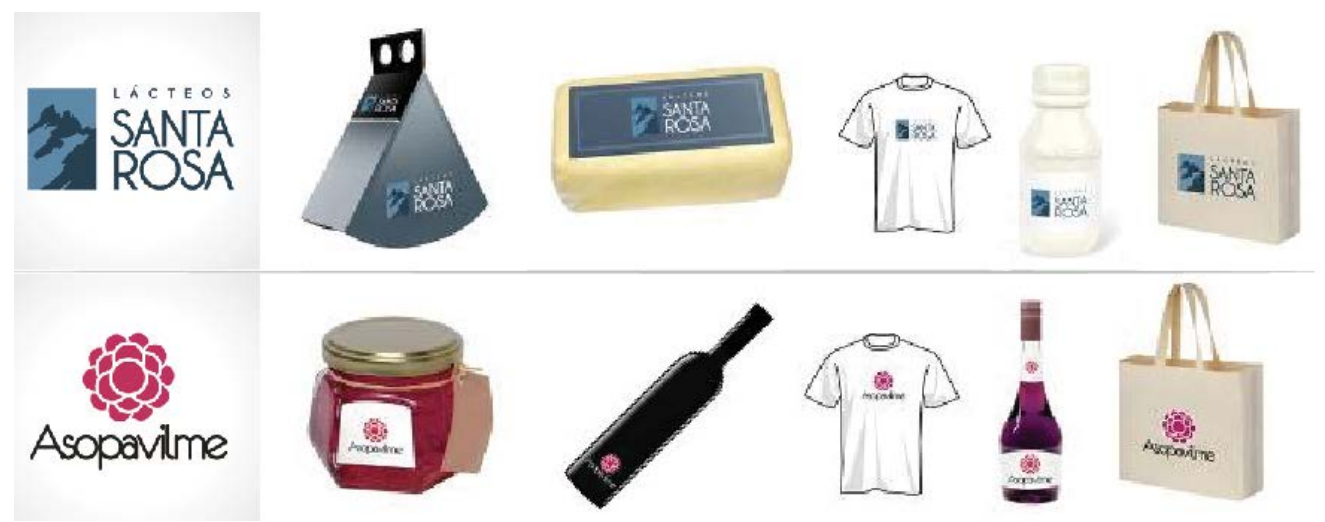

Figura 6 - Propostas desenvolvidas para Lácteos Santa Rosa e Asopavilme.

Fonte: acervo NGD/LDU UFSC.

Na Mesa Julia e Chocomelia (Figura 7), observou-se que seus produtos careciam de aspectos diferenciais para despertar o interesse do mercado nacional, visto que o cacau é um produto de baixo consumo no país. Os produtores regionais também viam poucos horizontes na atividade do cultivo do cacau, resultando no distanciamento de seus filhos. Como oportunidades observaram-se: oficinas de capacitação; materiais gráficos contendo instruções a respeito dos corretos processamento e manejo do cacau e a inclusão das crianças. Propôs-se o desenvolvimento das marcas coletivas geográficas, enaltecendo a procedência do cacau destes produtores.

\footnotetext{
${ }^{3}$ A professora Astrid Uzcátegui (Universidad de los Andes) foi responsável pelo projeto na Venezuela.

4 Usada para atestar a conformidade de um produto ou serviço com determinadas normas ou especificações técnicas, notadamente quanto à qualidade, natureza, material utilizado e metodologia empregada (BRASIL, 1996).

${ }^{5}$ Usada para identificar produtos ou serviços provindos de membros de uma determinada entidade (BRASIL, 1996).
} 


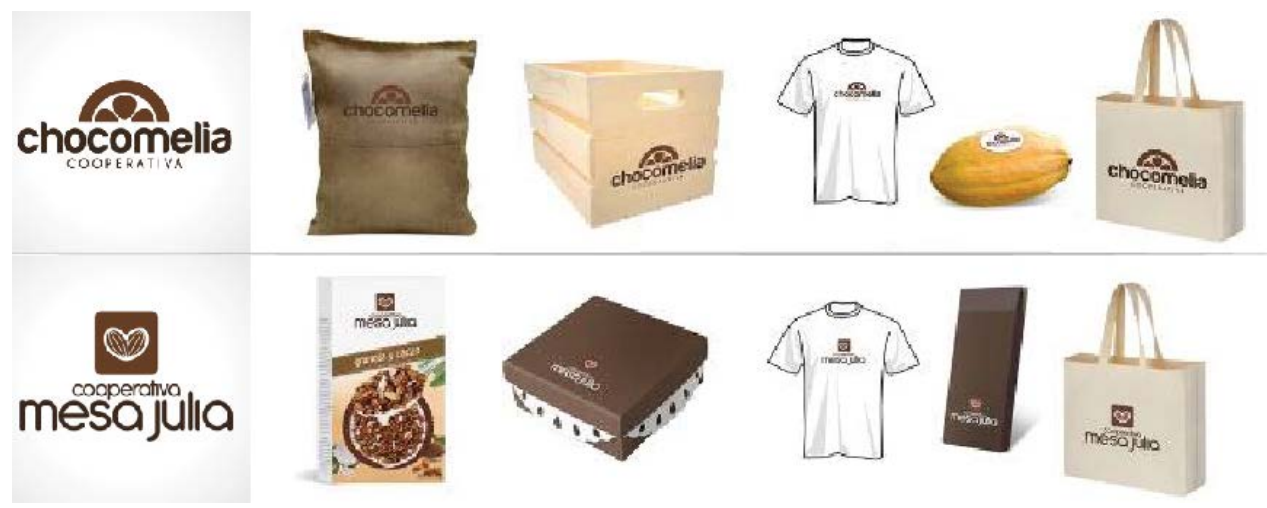

Figura 7 - Propostas desenvolvidas para Mesa Julia e Chocomelia.

Fonte: acervo NGD/LDU UFSC.

No Brasil, o projeto foi desenvolvido no sul do estado de Santa Catarina com a Coofasul - cultivo de uvas e cana-de-açúcar e produção de vinhos, sucos de uva e cachaça na cidade de Garopaba; e a Cooperlagos - com derivados da mandioca na cidade de Urussanga (Figura 8). Foi observado que as cooperativas possuíam identificação e a embalagens precárias, sem conhecimento e acompanhamento técnico sobre questões como unidade visual, padronização, normas e preceitos estabelecidos pela Anvisa - Agência Nacional de Vigilância Sanitária. Verificou-se também a falta de valorização e de qualidade aparente dos produtos, tornando-os pouco atrativos e impactando diretamente no desempenho das vendas.

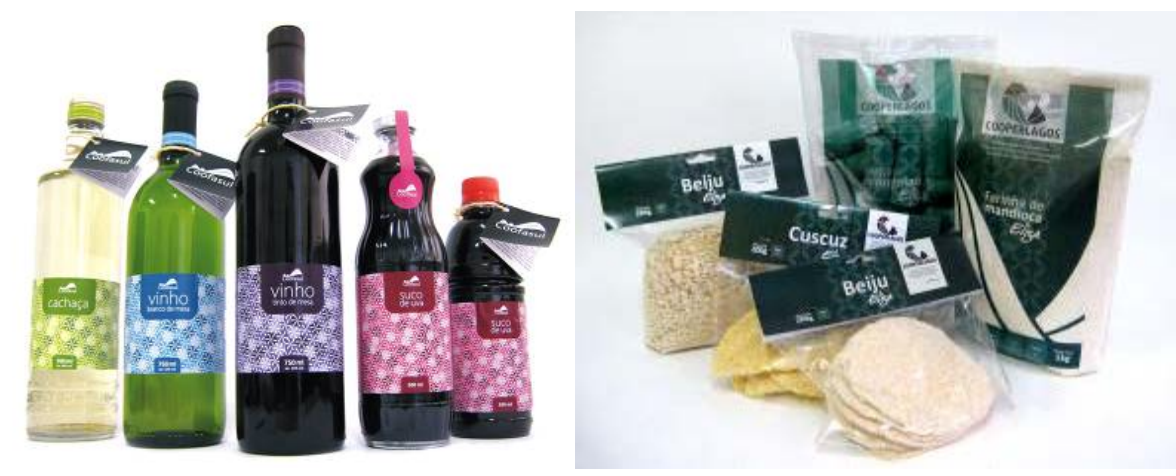

Figura 8 - Marca gráfica aplicada em rótulos e embalagens Coofasul e Cooperlagos, respectivamente. Fonte: acervo NGD/LDU UFSC.

Para finalização do projeto, foi organizado o 10 Seminário Internacional de Gestão de Design: valorização da produção de pequenos grupos através da identificação e proteção legal, na cidade de Florianópolis, que contou com palestrantes de instituições do Brasil, Portugal, Venezuela, Estados Unidos, Peru e Costa Rica.

\subsection{Florianópolis}

De 2007 a 2010 a atuação aconteceu junto à Amprosul, uma associação de produtores de mexilhões e ostras, localizada em Florianópolis. A partir do diagnóstico, notaram-se dificuldades na comercialização e na divulgação, fragilidades quanto à identificação do grupo e dos produtos, falta de embalagens, irregularidades no registro legal e incertezas sobre a gestão da associação. Foram então propostas ações de legalização do grupo; desenvolvimento de identidade visual, com marca gráfica e 
principais aplicações - embalagens, rótulos, website e vídeo institucional (Figura 9) e levantamento dos hábitos e costumes do público-alvo no consumo de mexilhões.
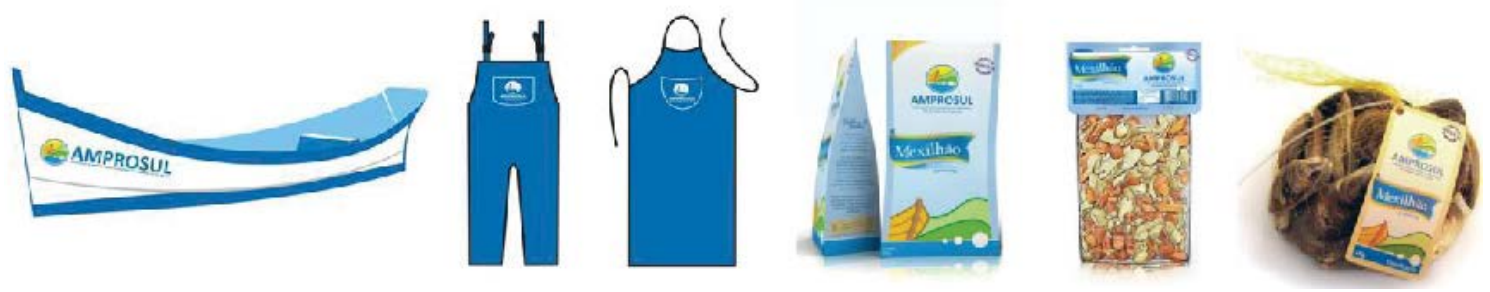

Figura 9 - Marca gráfica da Amprosul aplicada em diversos materiais desenvolvidos. Fonte: acervo NGD/LDU UFSC.

A pesquisa com consumidores ocorreu por meio de um questionário online, no qual foi possível obter informações a respeito de frequência de consumo, hábito de compra, preferência pela forma de comercialização, entre outros, contribuindo para a inserção da Amprosul no mercado de modo mais estratégico.

\subsection{Governador Celso Ramos}

Em 2010 também se iniciou o projeto com a Mar de Açores, uma pequena empresa voltada para a produção de ostras e mexilhões na cidade de Governador Celso Ramos. Verificou-se que a Mar de Açores tem como principal objetivo a ampliação das vendas no varejo para o consumidor final, visto que sua comercialização estava destinada em maior parte a fornecedores, onde o preço de venda acabava sendo $20 \%$ menor do que desejavam. Entre as fragilidades identificadas estavam: dificuldade de inserir o produto em supermercados, devido, entre outros motivos, à fragilidade de sua comunicação; fragilidades quanto à usabilidade das embalagens e do site; marca gráfica sem registro no INPI; embalagens não apresentam atributos do produto e diferenciais da empresa; também se verificou que a embalagem necessita de maior apelo de compra para atingir o público alvo desejado. Nesse sentido, foi proposto o desenvolvimento de embalagens e rótulos para comercialização dos produtos em bares, restaurantes e supermercados, com maior apelo de consumo e adequando às demandas e necessidades dos consumidores finais, bem como se atentando a aspectos de legislação (Figura 10).
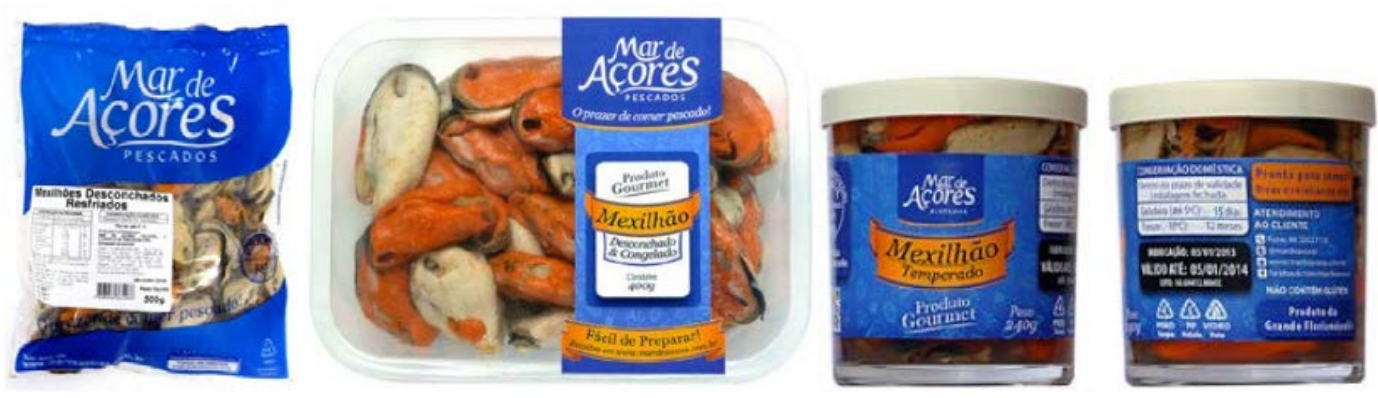

Figura 10 - Embalagens desenvolvidas para a Mar de Açores.

Fonte: acervo NGD/LDU UFSC.

Também se realizou uma pesquisa com consumidores por meio de um questionário, contribuindo para o levantamento de necessidades originadas nos momentos de compra, preparo de alimentos e para o processo de hierarquização das 
informações na embalagem. Ao fim do projeto, outra pesquisa com consumidores foi efetuada, via internet, para conhecimento do perfil dos consumidores e validação dos materiais gráficos.

\subsection{Joinville e Blumenau}

Em parceria com a Epagri e por meio do Programa SC Rural, desde 2014, encontra-se em desenvolvimento o Projeto de Gestão de Empreendimentos Rurais e Pesqueiros, com atuação direcionada, inicialmente, para as regiões de Joinville e Blumenau, localizadas ao norte no estado de Santa Catarina. Até o momento, todas as vinte e seis propriedades foram visitas in loco, gerando um diagnóstico preliminar que possibilitou a identificação das fragilidades e potencialidades, as quais estão sendo avaliadas com a finalidade de estabelecer as prioridades e, consequentemente, definir as ações de design para cada uma delas.

\section{CONSIDERAÇÕES FINAIS}

Durante os quinze anos de trabalhos com a aplicação do design na agricultura familiar é possível perceber diversas fragilidades e dificuldades enfrentadas pelos produtores. Em geral, destacam-se: falta de identificação visual no que diz respeito aos produtores, cooperativas e/ou associações e produtos; produtos de boa qualidade em embalagens inadequadas; dificuldades de acesso a informações de mercado, tendências, legalização e gestão da atividade; limitadas ações de divulgação; dificuldades organizacionais em geral; limitadas ações de divulgação; entre outras (MERINO, 2010; TEIXEIRA, 2011). Neste contexto, verificam-se oportunidades de contribuição de projetos de design e de sua visão voltada ao usuário/consumidor, direcionando para uma percepção de qualidade e auxiliando em sua entrada no mercado. Com o desenvolvimento de marcas gráficas, por exemplo, contribui para a identificação visual dos agricultores, diferenciando-os no mercado por meio da evidenciação de aspectos distintivos quanto à cultura, forma de produção, entre outras características próprias. Embalagens adequadas também contribuem para 0 transporte e proteção dos produtos, além de serem uma interface direta entre empresa e usuário, necessitando a utilização de recursos visuais que o diferenciem entre tantas outras opções. Observa-se com este artigo que o design pode se utilizar de diferentes ações visando à identificação e à valorização destes grupos produtivos de características familiares, contribuindo para sua inserção no mercado e diferenciação.

\section{AGRADECIMENTOS}

CNPq, FAPESC, CAPES, FAPEU, EPAGRI e, em especial, aos agricultores familiares participantes dos projetos.

\section{REFERÊNCIAS}

AIAF. ANO INTERNACIONAL DA AGRICULTURA FAMILIAR. 2014. Disponível na internet por http em: <http://www.fao.org/family-farming-2014/pt/>. Acesso em 19 abr. 2016.

ALTMANN, R.; MIOR, L.C.; ZOLDAN, P. Perspectivas para o sistema agroalimentar e o espaço rural de Santa Catarina em 2015: Percepção de representantes de agroindústrias, cooperativas e organizações sociais. Florianópolis: Epagri, 2008. 
ARAUJO, Massilon J. Fundamentos de Agronegócios. São Paulo: Editora Atlas, 2007.

ARIAS et al. Smallholder integration in changing food markets. Rome: FAO, 2013.

BENEZ, Mara et al. Programa Estadual de Competitividade da Agricultura Familiar Santa Catarina Rural: Avaliação Ambiental. 2010.

BRASIL. Lei n. 9.279, de 14 de maio de 1996. Regula direitos e obrigações relativos à propriedade industrial. Diário Oficial da União, Brasília, DF, 15 maio 1996.

FAO. FOOD AND AGRICULTURE ORGANIZATION OF THE UNITED NATIONS. World Food Day. 2014a. Disponível na internet por http em: <http://www.fao.org/world-foodday/home/en/>. Acesso em: 19 abr. 2015.

. Towards stronger family farmers. 2014b. Disponível na internet por http em: <http://www.fao.org/3/a-i4171e.pdf>. Acesso em 25 abr. 2016.

FERNÁNDEZ, Silvia; BONSIEPE, Gui (Org.). Historia del diseño en America Latina y el Caribe: Industrialización y comunicación visual para la autonomía. São Paulo: Editora Blücher, 2008. 371 p.

FETAESC. Federação dos Trabalhadores na Agricultura do Estado de Santa Catarina. Disponível na internet por http em: <http://www.fetaesc.org.br/>. Acesso em 25 abr. 2016.

GOVERNO DO ESTADO DE SANTA CATARINA. Agricultura e Pesca. Disponível na internet por http em: <http://www.sc.gov.br/index.php/agricultura-e-pesca>. Acesso em 25 abr. 2016.

MERINO, Giselle Schmidt Alves Díaz. A contribuição da gestão de design em grupos produtivos de pequeno porte no setor da maricultura: o caso AMPROSUL. 2010b. 184 f. Dissertação (Mestrado) - UFSC, Curso de Pós-Graduação em Design.

PORTAL BRASIL. Agricultura familiar produz $\mathbf{7 0 \%}$ dos alimentos consumidos por brasileiro. Brasília, 24 jul. 2015. Disponível na internet por http em:

<http://www.brasil.gov.br/economia-e-emprego/2015/07/agricultura-familiar-produz70-dos-alimentos-consumidos-por-brasileiro>. Acesso em 25 abr. 2016.

SEBRAE. Infográfico horticultura com design. 2015. Disponível na internet por http em: <http://www.sebrae.com.br/Sebrae/Portal\%20Sebrae/Anexos/hortifrutisebrae.pdf $>$. Acesso em: 24 maio 2015.

TEIXEIRA, Julio Monteiro. Identificação e proteção: o design valorizando grupos produtivos de pequeno porte. Florianópolis, 2011. 177 f. Dissertação (Mestrado) UFSC, Curso de Pós-Graduação em Design. 